Topografias da Linguagem

A4) 


\title{
Poesia visuAl E IMAGENS DA MATÉRIA
}

\author{
Roland de Azeredo Campos \\ Instituto de Física, UnB
}

\begin{abstract}
RESUMO
O propósito deste artigo é discutir alguns poemas visuais pósconcretos no contexto da teoria da imaginação poética proposta por Gaston Bachelard, baseada nos arquétipos dos quatro elementos (ar, água, terra e fogo). Os poemas aqui considerados estão diretamente relacionados ao tema dos elementos.
\end{abstract}

PALAVRAS-CHAVE

Poesia visual brasileira. Poesia concreta. Bachelard. Imaginação poética.

\section{INTRODUÇÃO}

O espaço nasceu irmanado à matéria-energia. A explosão inaugural, responsável pelas contorções evolucionárias de nosso cosmos e pela disseminação progressiva de luz e de partículas, foi também modelando, em esforço paralelo, o peculiar arcabouço de tempo-espaço que hoje, circunstancialmente ou não, abriga neutrinos, metagaláxias, bactérias, humanos, nanorrobôs... Em contenda talvez inglória ansiamos decifrar tal cenário geometrodinâmico gigantesco, do qual não podemos nos apartar.

Da mesma forma, nossa imaginação, de um lado, e o mundo exterior, de outro, parecem integrados em simbiose. Alguns pensadores, desde a Antigüidade, têm seguido essa pista. Empédocles de Agrigento (século V a.C.) atribuiu a base da realidade, tal qual se mostra à nossa percepção, e da própria vida, a combinações dos quatro elementos, conciliando, assim, o imóvel (Parmênides) e o mutável (Heráclito). Aristóteles, com sua hipótese da scala naturae, propôs um entrelaçamento do orgânico e do inorgânico, que, reelaborado por Leibniz, evocou uma possível afinidade entre o intelecto humano e a matéria em geral. No século XIX Darwin estabeleceu a teoria da evolução, pondo em destaque o vínculo inevitável entre os animais desprovidos de consciência e aqueles (sapiens) capazes de pensar e de sentir a vida e a morte. Esta aptidão seria, aliás, um índice de superioridade, embora Jorge Luis Borges pondere, com humor e sabor, em seu famoso conto "O imortal", que os irracionais teriam o dom, tão cobiçado, da imortalidade, por ignorarem estar condenados a perecer.

Gaston Bachelard, um dos maiores intérpretes da revolução epistemológica promovida pelas teorias quântica e relativística, dissecou com igual desenvoltura as 
relações entre a imaginação e a matéria. Denominou "imagens da matéria" as formações sígnicas, geradas no ato criador, reveladoras de uma profundidade de abordagem. Quis o filósofo francês acentuar, com isso, a importância do mergulho sensível na essência, na esfera nuclear dos entes. Perseguindo esse vetor, formulou uma "lei dos quatro elementos", aplicável à criação poética (sígnica, em geral): o fogo, o ar, a terra e a água forneceriam, metaforicamente, diretrizes ao gesto inventivo, nutrindo-o de "substância", ou seja, de regras internas e de especificidade. Tal conceito, na aparência filiado à psicologia ou, quem sabe, à ficção, manifesta, a meu ver, afinidade com as metas da semiótica no trato do signo estético. Pois a figura dos quatro elementos aponta para o nível mais denso e fundamental da matéria artística, e para a mirada certeira que distingue um representame estético relevante de um mero jogo formal. Como um operador diferencial atuando sobre um espaço de funções, a mente imaginativa se posiciona para alcançar o cerne objetal. Elabora uma espécie de algoritmo, que assegura, nos casos bem-sucedidos, uma "solução" de qualidade.

Não tenho, aqui, a aspiração de discutir detalhadamente o programa bachelardiano dos elementos, nem de julgar seu alcance para a análise de exemplares artísticos. Creio, no entanto, ser viável tomá-lo, em certos casos, como fonte inspiradora. A poesia visual (ou intersemiótica), em particular, parece favorecer, por sua escala de expedientes, a condução do receptor ao imo da matéria estética. Os componentes não-verbais ajudam a configurar uma espécie de diagrama, onde as relações entre as partes, moldando o todo, instituem o ente poético.

O propósito deste artigo é focalizar alguns poemas visuais em que as escolhas temáticas dos autores evocam de imediato o approach de Bachelard. São trabalhos pouco divulgados, de autores brasileiros (nem todos, diga-se, praticantes exclusivos da referida modalidade), produzidos nas três ou quatro últimas décadas, e que se inserem, portanto, num contexto pós-concreto de experimentos com a linguagem. Sob os influxos do ar, da água, da terra e do fogo, e assumindo a liberdade de buscar, eventualmente, apoio em conceitos da ciência, tentarei levar ao leitor amostras das realizações desta vertente de nossa poesia.

\section{AR}

Pálpebras cerradas, olfato aguçado. Invadem as narinas os costumeiros $78 \%$ de nitrogênio, os 21\% de oxigênio. Ar. Vida. Agora, olhos abertos. Erguidos rumo ao zênite. Azul-do-céu. Lá, mais alto, o ar rareia. Voa. Mais acima, a $380.000 \mathrm{~km}$ da Terra, na Lua, inexiste. "Desoxigênesis". Cá, no horizonte, montanhas. Contorno das montanhas: mulher deitada. Azul de novo. "Oxigênesis".

O livro-poema Oxigênesis, de Villari Herrmann, com design de Julio Plaza, foi lançado em 1977. Edições STRIP: Sindicato dos Trabalhadores na Indústria Poética. A 
concepção envolve, em primeiro lugar, um uso da simetria rotacional, para todas as páginas: um giro de $180^{\circ}$, invertendo a folha, provoca dubiedades na interpretação das imagens. Um raio vira um rio, com seus afluentes. Uma árvore, invertida, recorda um pulmão cortado, em vista frontal. A silhueta de um corpo feminino, estirado na horizontal, mirando o limpo azul do céu, pode ser enxergado, na rotação, como um contorno de vales e montanhas. $\mathrm{O}$ azul-claro é a cor de fundo de todas as pranchas do livro. Em uma das páginas, um agregado composto por dois triângulos e uma elipse, em tom prata, perfilados em diagonal, permite a leitura: VOA. O autor faz menção, ainda, a seu poema "Koito", de 1971, que acasala a letra K com o número oito. Em Oxigênesis o 8 (em cor rosa) se acomoda, deitado, acolhendo o K (em azul-escuro, no original). Na orientação contrária vemos outra posição de cópula.
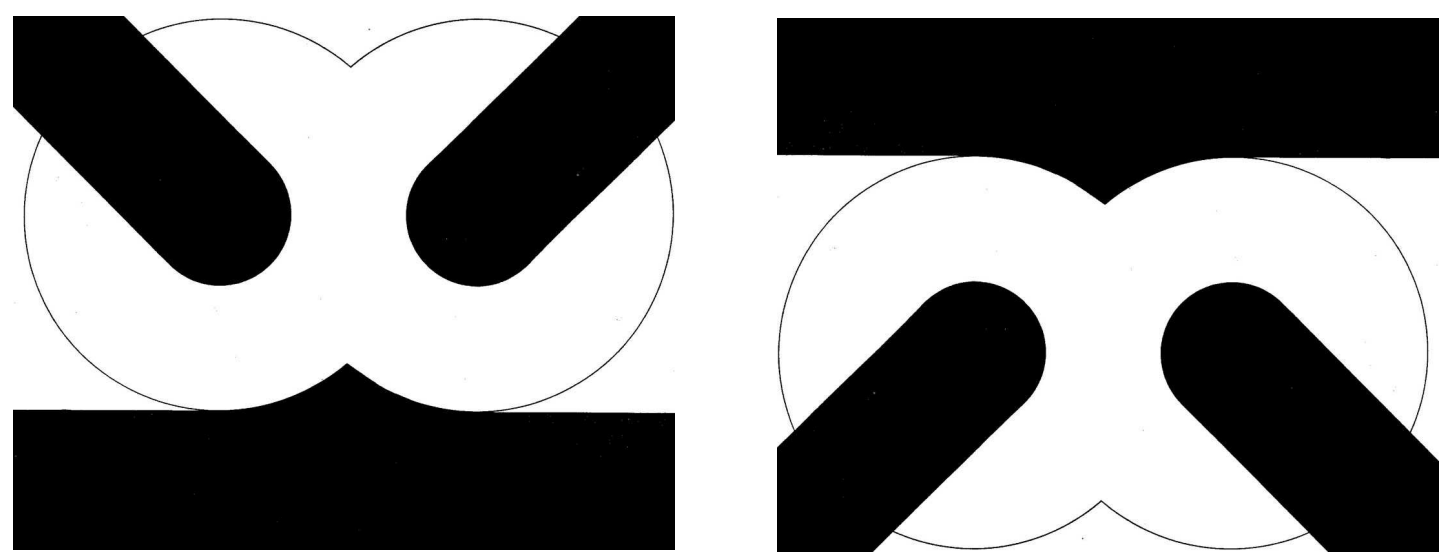

Fragmento do livro-poema Oxigênesis, de Villari Herrmann.

Nos dois casos a simetria, aliás, bastante freqüente no reino animal, é especular (bilateral), em torno de eixos verticais que passam pelo centro de cada uma das páginas. Os olhos esquerdo e direito, por exemplo, são simétricos em relação a um eixo que, partindo da testa, transpõe o nariz. Dizia o genial matemático Hermann Weyl que a direita e a esquerda são da mesma essência (sem conotação político-ideológica, acrescento): a reflexão no espelho é um automorfismo (grupo de transformações que deixam invariável a estrutura do espaço). E Herrmann (Villari) aplica eficazmente esse conceito. Um dos traços de seu estilo é a habilidade para alcançar uma solução original partindo de um mínimo de elementos, sempre no território das experiências-limite. Outros notáveis trabalhos seus, publicados nas décadas de 70 e 80, são: "A desoxigênesis", "Sombras", "Poder/podre", "Valsa do minuto", "Hermanêutica" (este com a colaboração criativa de Renato Ghiotto).

Eva. Ela é mais. Matriz. Nutriz. Nasceu. Viveu. Viveu. Virou vapor. Esvaeceu-se. Fez-se aérea. Nebulosa. Andrômeda, Berenice, Cygnus, Lira, Rosa... 
"Evanescente", de Edgard Braga, é um dos itens de seu instigante livro Algo, de 1971. Aí encontramos vários poemas dignos de registro ("Estrela ilhas", "Indefinito e lúcito", "Pássaro morto na noite"). Cada um deles é exibido numa página dupla, a segunda mostrando o negativo da primeira refletido no espelho (mais uma vez a simetria bilateral). Décio Pignatari, Luiz Ângelo Pinto e Francisco Del Rio Andrade respondem pelo lay out e pela diagramação. Os títulos vêm no início, com tradução para o inglês e para o francês. Evanescente, então, é também Evanescent (Eve being born) e Evanescent (Ève naissante). A Eva do poema recorda uma boneca infantil, tracejada com pinceladas lestas, mas tênues, cabeça, tronco e membros rarefeitos. No ventre se lê (não sem algum esforço, pois as letras têm tamanho reduzido): EVA/ nescente. Na margem inferior direita Braga assina e data: 1969. O negativo esvanesce a pobre Eva. A inscrição citada se perde. Restam minúsculas manchas brancas, lembrando vestígios estelares em galáxia remota.

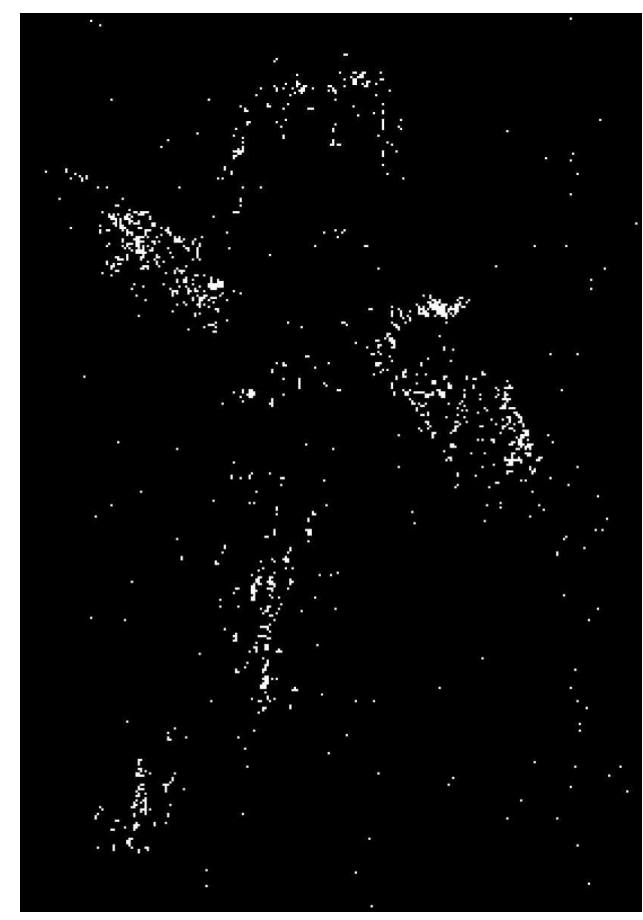

Página do livro Algo, de Edgard Braga.

O polvilho evoca a recessão voraz que afasta entre si os aglomerados de matéria do universo (lei de Hubble), condenando-os a um degredo cósmico. Big bang: nascimento, energia, vida. Big crunch: degradação, entropia, morte. Ela nascente. Ela nescente. Vaporosa, de(s)composta, Eva se vai.

\section{ÁGUA}

Mar se mascara na linha do céu-dia. Espelha e espalha o índigo (formidável dispersão de Rayleigh!). Após o ocaso, mar se fina na faixa do céu-noite (Olbers, por que é escuro à noite?). Se chove, embate aquático. Treva. Horizonte de evento reveste buraco negro. Limites. Limite, de Mário Peixoto. "Ideograma-limite", de Francisco Kaq. 
Em seu "Ideograma-limite" (hommage a Mário), extraído do livro Aresta/Hagoromo (1990), Kaq capta e expede em forma poética, e com sucesso, o tônus do filme. No poema, letras/sílabas flutuam no mar-espaço do papel, em disposição quase circular, desafiando o olho-mente do receptor a "descobrir" palavras.

\section{G $E$}

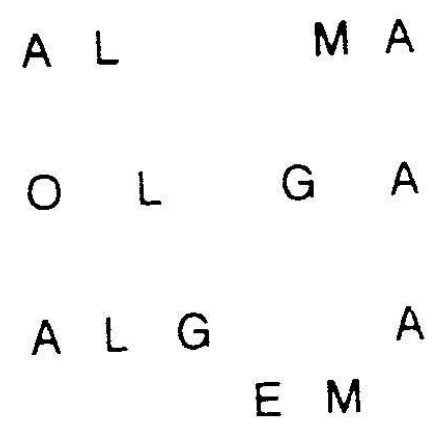

Página de Aresta/Hagoromo, de Francisco Kaq.

"Algema”, "alma”, "Olga", "alga" referenciam momentos/eventos cruciais do filme. Nele aparece, logo no início, Olga algemada. Em seguida, após algumas fusões de fotogramas, ela é vista com outros personagens, num barco parado, perdido no mar imenso. Um corte converte a imagem de Olga, abatida, em outra: a da linha do horizonte, repartindo ao meio céu e mar. O leitmotiv é o contraste entre o mar "ilimitado" e os limites impostos pelas amarras/algemas da vida aos "náufragos" do barco, que passam então a recordar seus dramas pessoais e a desvelar suas almas angustiadas. No final, destroços. Olga se mostra "como uma alga", os cabelos boiando na água. Revém, por meio de fusão, a cena das algemas. Depois: mar cintilante; mar sombrio; uma elevação; abutres; vazio; fade out, negro. O poema de Kaq mostra a palavra "olga" alinhada horizontalmente, prensada entre duas "algemas", limites-vocábulos inferior e superior. A formatação arredondada iconiza a algema, conferindo aos trâmites ideogrâmicos (fusões, montagens) um adicional caráter caligrâmico. Note-se, ainda, a presença de colunas verticais vocálicas, quase-simétricas, à esquerda $(\mathrm{a} / \mathrm{o} / \mathrm{a})$ e à direita $(\mathrm{a} / \mathrm{a} / \mathrm{a})$, confinando as dispersões ondulatório-marítimas, ritmadas, do "l" e do "g". Por esta via, também, o poema remete ao filme. Já se disse, aliás, que Limite é cinema "de imagens e de ritmos. Ritmos de todas as espécies" (Octávio de Faria). E esta preamar rítmica, atratora de entonações e sonoridades, decerto marcou o autor de "Ideograma-limite", que vem praticando, ultimamente, uma original oralização de seus trabalhos, somandose a performers de destaque nacional, como Arnaldo Antunes e Ricardo Aleixo.

É curioso observar que um poema de Pedro Xisto, “Águas Glaucas” (1960), faz emergir, em ambiência náutica, uma ondeante e plural palavra "algas", identificada na vertical, em negrito. 
"Riocorrente". Rio correntes. Tudo. Rios. Reais, nacionais, existenciais, alegres, doridos. Siso. Riso.

"Aguamaré". Assim Antonio Risério batizou um poema seu, de 1992, integrante do livro Fetiche (1996). A respeito deste diz Risério: "não existiria, assim como está, sem o engajamento de Luís Eduardo Resende de Brito, o Resa, companheiro dos bons tempos da Bric-a-brac, peripécias experimentais em Brasília [...]”. Resa, de fato, arrasa, com sua esmerada computação gráfica. Também André Luyz Sã-tos e Arnaldo Antunes, entre outros, colaboram como arte-finalistas.

As doze linhas-versos de "Aguamaré" desfiam denominações de rios brasileiros (“.../rio do peixe rio da cachoeira rio do piolho/ rio vermelho rio negro rio pitanga/.../rio da praia rio do antonio rio da casca/ rio alegre rio das dores rio correntes/...”). Os nomes são impressos ora em cor azul sobre fundo branco, ora em branco sobre azul. Azul-córrego sorvendo céu. Riachão onde se afogam/afagam vermelho e negro. Na linha final, a chave de ouro: "rio de todos rio de tudo rio de mim". Riso Risério. Ou, para reproduzir, nesse contexto, um trocadilho do autor: "ri melhor quem ri sério".

\section{TERRA}

Além do horizonte, serras. "Um campo tem terra". Tem silêncio. Silêncio ocre. Enraizado. Plantado. Prado às vezes é campo. Campo às vezes é de visão. "É tudo que se vê".

O poema "Campo", de Arnaldo Antunes, está em seu livro Nome (1993), para o qual também colaboraram Célia Catunda, Kiko Mistrorigo e Zaba Moreau. Nome vem ainda acompanhado de um vídeo. Arnaldo, como se sabe, é um artista multimídia, compositor e performer, além de poeta. Em "Campo" surpreende-nos com um procedimento inusitado. O tema de terra é exposto em frases simples, encadeadas consistentemente, porém trabalhadas de modo a exigir a participação do fruidor. As letras, tratadas em computador, são esticadas verticalmente e espremidas na horizontal. Para alcançar a leitura, devemos posicionar a folha numa angulação favorável. Então surge: "Um campo tem terra E coisas plantadas nela A terra pode ser chamada de chão É tudo que se vê Se o campo for um campo de visão". E saltam aos olhos os alongados traços verticais, em especial dos "p" (como que fincados no "chão" do papel) e dos "l"/ "d" (lembrando caules de plantas em prumo voltados para o céu). Iconizam-se, assim, tanto a penetração radicante no solo quanto a visão alçada para cima. Up e down são as duas orientações possíveis na reta zenital, como no eixo de polarização do spin das partículas. E a compactação horizontal das frases constrói pictoricamente uma plantação ou um relvado. 
Cabe aqui rememorar o poema "Terra" (1956), de Décio Pignatari, onde as letras "t", “e”, "r" e "a" perfilam-se gerando múltiplas leituras ("ara”, "ter”, "rara”, etc.), e "cavando" dois sulcos convergentes que conotam a aradura.

Lições estéticas da terra...

Rés-do-chão. Laje. Sepultura. Um morto. Sua energia decerto persiste. Pervaga o planeta. Irradia. Lança dados. Persegue ainda, talvez, o LIVRO inacabado. (Le Livre! Estará oculto em algum canto da "biblioteca de Babel" borgiana?). Mallarmé! Num jazigo retangular, cercado de letras. Figurando livros. Tombeau-livre.

"Le tombeau de Mallarmé", de Erthos Albino de Souza, data de 1972. O poema consta de dez folhas contendo gráficos, que parecem ter sido extraídos de um paper de física. Conforme depoimento do autor, as seqüências gráficas foram obtidas por meio de um programa de computador (essas máquinas, na época, eram enormes; engoliam cartões perfurados e cuspiam largas tiras de papel). Um problema de hidrodinâmica (escoamento de fluidos em seções quadradas) forneceu a base. A partir de uma correspondência entre variações de temperatura de um fluido e as letras do nome "Mallarmé", advieram diagramas com retângulos (ou quase) na área central, circundados pelos "A", "E", "L", "M", "R" (nem todos presentes sempre), em distribuições diversas. Foram escolhidas então dez soluções de aspecto adequado. A derradeira é a que melhor exibe a intenção do trabalho.

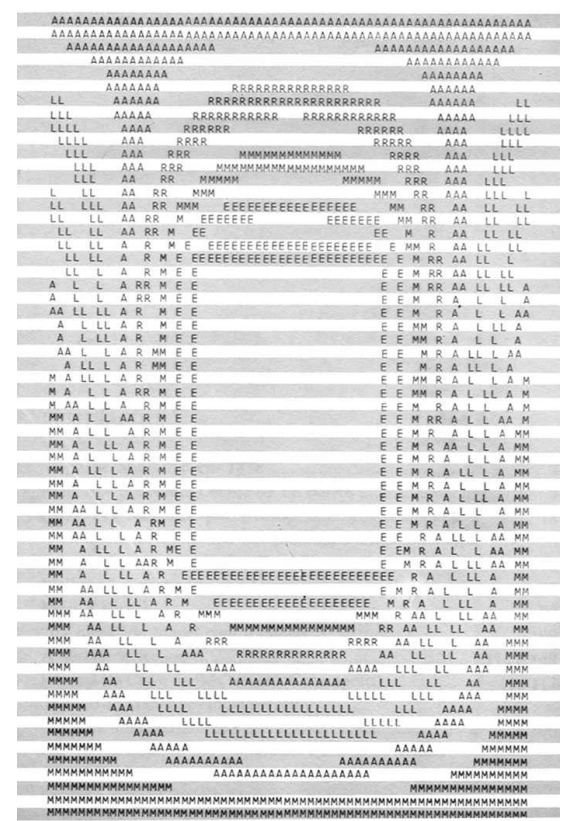

Última página de "Le tombeau de Mallarmé”, de Erthos Albino de Souza. 
O retângulo do centro, além da referência ao túmulo, alude ao formato usual de um livro. Mallarmé ("tudo existe, no mundo, para acabar num livro") perseguiu o projeto de um livro integral (Le Livre), onde os poemas, potencialmente presentes, se materializariam através de alternativas combinatórias. A composição de Erthos evoca, ainda, o conhecido "Le tombeau d'Edgar Poe", homenagem do autor de Un coup de dés ao criador do romance policial.

Erthos, engenheiro de profissão e extraordinário poeta, desenvolveu técnicas computacionais aplicáveis à poesia. Editou a revista Código, onde foram publicados alguns de seus trabalhos, como "Soneto alfanumérico" e "Samsara - a John Lennon". A capa do n. 10 da revista (1985) traz sua luminosa versão para o poema "Cidade/city/ cité", de Augusto de Campos. Outra de suas realizações é "Volat irrevocabile tempus" (Atlas-Almanak, 1988), em que o rosto de Brigitte Bardot é deformado por meio de um software, tornando-se serpeante, e esfumaçando-se aos poucos.

\section{FogO}

Feu. Fogo. Ele mesmo, o elemento. Matéria. Mundo. Terceiro. Tiers monde. Matière. Misère... Sombra. Quarto. Retiro. Bang. Tiro. Coup de feu.

Aqui \& agora (Edições Dubolso, do poeta visual Sebastião Nunes, 1981) assinala o início poético de Carlos Ávila. "O terceiro mundo", um dos poemas de Aqui \& agora, expede em letras brancas sobre fundo preto: "o terceiro mundo/ vai explodir/ no quarto escuro/ um segundo/ e o primeiro tiro". Explosão e tiro sugerem o elemento fogo, o feu bachelardiano, que teria, comparado à água (elemento transitório, metamorfose ontológica essencial entre a terra e o fogo), menor uniformidade, e um caráter masculino (agressivo) mais acentuado (A água e os sonhos). Um tiro detona/denota um projétil/ projeto belicoso. A chama expelida pela arma, acasalada ao estrondo, denuncia um anseio assassino. No escuro taciturno o efeito se amplifica. No jogo com os numerais ordinais do poema de Carlos Ávila, o primeiro tiro vem no fim, na quinta linha. O terceiro mundo estremece. No quarto: breu. O quadro é negro. Contrapõe-se ao bleu celeste e aquático. (Bachelard: "na noite da matéria florescem flores negras"). No mesmo Aqui \& agora, outro exemplar ígneo: "BROCA/ falha na alma de uma boca de fogo". Um objet trouvé pinçado em dicionário. Nesta acepção de "broca", a "alma" é a parte interior, o núcleo explosivo da boca-de-fogo. As conotações poéticas do "verbete" são bem divertidas.

Menciono aqui, por associação temática, mais uma "consunção" estética. Tratase de um poema sem título de Aldo Fortes, incluído na caixa Zero à esquerda, editada por Omar Khouri e Paulo Miranda, em 1980. No poema, apresentado em cartão de formato retangular, as palavras, fragmentadas, escorrem verticalmente, em faixa estreita, 
na margem direita. O começo é: "9o ciga/ rro/ o/ es/ porro/ cr/ es/ ce/...". A chama do cigarro sinaliza o conturbado estado emocional do protagonista. O desfecho: "nem/ tempo/ nem/ tudo/ bala/ basta".

\section{II}

No prisma de Newton, luz. Geométrica, iriada. Optics! Senos de ângulos, índices de refração. No cume da pirâmide, sol. Rescaldo. Ra! Bola de fogo inscrita na pele da erma areia. Papiro. No verso, chama.

O livro, sem título, de Florivaldo Menezes (Edições Invenção, 1972), é bastante original. Traz na capa a figura de uma faca, índice, talvez, do propósito radical do autor. A esse respeito, Ronaldo Azeredo, em seu prefácio à obra, declara: "Menezes preferiu o mais difícil, o anonimato artístico, lançando poemas de pura criatividade visual, enigmas para o leitor comum". Um desses "enigmas" é "Papiropirâmides Monopol". Duas páginas adjacentes com fotos de um isqueiro (na segunda este é acionado, produzindo a chama) convidam-nos a olhar um encarte, preso à última capa. Nele se lê: "volteie com chama, sem queimar, todo o centro do verso, podendo chegar ao extremo". E logo abaixo: "e g i p c i O". Ao realizarmos a operação indicada, roçando cuidadosamente uma chama de isqueiro no avesso do encarte, vemos surgirem, na frente, duas formas piramidais, espraiadas simetricamente, a partir do centro, para a esquerda e para a direita. À esquerda, lemos: "egipcia". À direita: "egipsiu". O mistério, então, vai sendo aclarado. Os significantes-pirâmides revelam uma bifurcação de significados. De um lado, o silêncio milenar ("psiu") das tumbas egípcias; de outro, a lida operosa da indústria ("cia"), direcionada para o lucro. "Monopol", saliente-se, é a marca de um isqueiro caro, sofisticado, muito em voga na década de 1950. E, como nome, conduz de imediato a monopoly (monopólio, em inglês).

Há outros puzzle poems menezianos no livro, entre eles "Enigmao", "Taxi”, "A boa luz", "Reverexcia.", "Trampolíngua”. Todos eles merecedores de estudo mais minucioso. Note-se que um dos arte-finalistas, Franklin Horylka, prematuramente falecido, chegou a projetar, em parceria com Décio Pignatari, um insólito alfabeto vertical.

\section{DEVIR}

Hoje, em plena era digital, com internet e ciberespaço, as intervenções multimidiáticas se alastraram. Surgiram mesmo algumas modalidades exóticas de criação: poesia transgênica, música fractal, desenhos biomórficos... Até o computador tem feito suas artes, perpetrando, fagueiro e ligeiríssimo (por meio de softwares, é claro), pinturas, composições e poemas. Novas vias se abriram às "imagens diretas da matéria". O signo estético passou a assumir faces imprevistas. A "realidade virtual" expandiu os recursos do universo inventivo. Nesse ambiente amplificado, artistas e cientistas começaram a 
interagir intensamente, numa atividade perquiridora que chamo de "arteciência". Há projetos, na atualidade, conduzidos por equipes que incluem, por exemplo, biólogos, poetas, matemáticos, designers. Trabalhos intersemióticos como os que comentei neste artigo poderiam, por sua natureza, ser reelaborados proveitosamente com a utilização de técnicas modernas, convertendo-se em animações, em poemas tridimensionais, etc. As criações estéticas que Bachelard metaforizava recorrendo às substâncias/forças da natureza, aérea, aquática, terrestre e ígnea, agora se multifacetaram, e ressonam rumo ao desconhecido. Devir: vetor temporal que perfura o futuro. Ciber-, inter-, hiper-, multi-: espaço em expansão... Salut!

\section{A4}

\section{A B S TRACT}

The purpose of this article is to discuss some postconcrete visual poems in the context of Gaston Bachelard's theory of poetical imagination, which is based on the archetypes of the four elements (air, water, earth and fire). The poems considered here are directly related to the theme of the elements.

\section{KEYWORDS}

Brazilian visual poetry. Concrete poetry. Bachelard.

Poetical imagination.

\section{REFERÊNCIAS}

ALBINO DE SOUZA, Erthos. Le tombeau de Mallarmé. In: CAMPOS, Augusto de; PIGNATARI, Décio; CAMPOS, Haroldo de. Mallarmé. 3. ed. São Paulo: Perspectiva, 2002.

ANTUNES, Arnaldo. Nome. Rio de Janeiro: BMG, 1993.

ÁVILA, Carlos. Aqui \& agora. Belo Horizonte: Edições Dubolso, 1981.

BACHELARD, Gaston. A água e os sonhos. São Paulo: Martins Fontes, 1989.

BACHELARD, Gaston. A poética do espaço. In: Os pensadores. Bachelard. São Paulo: Abril Cultural, 1978.

BRAGA, Edgard. Algo. São Paulo: Edições Invenção, 1971.

HERRMANN, Villari. Oxigênesis. São Paulo: Edições Strip, 1977.

KAQ, Francisco. Aresta/Hagoromo. Brasília: Thesaurus, 1990.

MENEZES, Florivaldo. Livro s/ título. São Paulo: Edições Invenção, 1972.

RISÉRIO, Antonio. Fetiche. Salvador: Casa de Jorge Amado, 1996.

WEYL, Hermann. Simetria. São Paulo: Edusp, 1997. 